\title{
ESTUDO DE DIVERSAS VARIEDADES DE COPAS SOBRE DIFERENTES PORTA-ENXERTOS DA MANGUEIRA (Mangifera indica L.)
}

\author{
S. SIMÃO; O. NYLANDER; B. OTTASI \\ Departamento de Horticultura-ESALQ/USP, C.P. 9, CEP: 13418-900 - Piracicaba,SP \\ D. BARBIN \\ Departamento de Matematica e Estattstica-ESALQ/USP, C.P. 9, CEP: 13418-900 - Piracicaba,SP
}

\begin{abstract}
RESUMO: $O$ objetivo deste trabalho foi verificar a interferencia copa $x$ porta-enxerto no desenvolvimento da mangueira. As alturas e os diAmetros das copas foram tomadas uma vez em 1981, quando as 210 plantas atingiram 15 anos de idade. As variedades de copas estudadas foram as seguintes: Extrema, Oliveira Neto, Carlota, Imperial, Pahiri e Bourbon. Os porta-enxertos utilizados foram Espada, Extrema, Oliveira Neto, Carlota, Coco, Pahiri e Bourbon. Os dados foram analisados e a comparação das médias foi feita através do teste de Tukey em nível de 5\% de probabilidade. $O$ estudo mostrou que as variedades de copa, Oliveira Neto, Extrema e Bourbon atingiram uma altura e um diametro maior que as demais variedades.
\end{abstract}

Descritores: manga, porta-enxerto

\section{STUDY OF SEVERAL VARIETIES OF TREE CROWNS ON DIFWLRENT ROOTSTOCKS OF MANGO (Mangifera indica $\mathbf{L}$ )}

SUMMARY: The aim of this paper was to investigate the influence of the combination tree crown + rootstock on mango tree performance. The trees were selected according to height and crown diameter, measured once in 1981, using 210 trees, 15 years old at the beginning of the experiment. The Extrema, Espada, Oliveira Neto, Carlota, Bourbon, Coco and Pahiri varieties were used as rootstock and Extrema, Pahiri, Imperial, Oliveira Neto, Carlota e Bourbon were utilized as scions for tree crown development. Data were analysed by classical statistics, comparing means through the Tukey test, at a probability level of 5\%. The crowns Oliveira Neto, Extrema e Bourbon showed the highest heights and diametres.

Key Words: mango, rootstock

\section{INTRODUÇÃo}

A mangueira (Mangifera indica L.) é considerada originária da região Sudo-Burma (SINGH, 1967), onde predomina principalmente o clima monçônico, que se caracteriza por duas estações bem distintas, uma chuvosa e outra seca (CAMARGO et al., 1977). A manga é considerada como uma das principais frutas tropicais, devido à sua adaptação, e ao sabor de seus frutos (SIMÃo, 1971). No Brasil o cultivo de manga, que era feito nos anos 50 de pé franco, hoje está totalmente reformulado. Todos os atuais plantios são feitos com plantas enxertadas, e os porta-enxertos recomendados, têm sido quase sempre os de Espada ou Espadinha ou também chamado, comum ou Coco ou Coquinho (Simão, 1980).
Com a finalidade de conhecer o comportamento das variedades copas, também como portaenxertos é que se estabeleceu o presente estudo. Se os resultados se mantiverem favoráveis poder-se-á no futuro utilizar-se de sementes da própria variedade para a formação de mudas.

\section{REVISÃo DA LITERATURA}

SIMÃO (1955) estudando variedades comerciais de manga, determinou vários parâmetros sobre as variedades estudadas: tamanho do fruto, cor, sabor e porte da planta.

O desenvolvimento da mangueira se dá por surtos vegetativos que ocorrem desde agosto até março (SIMÃO, 1960) que determinam o desenvolvimento da mangueira. 
RUEHLE \& LEDIN (1955), relatam que surto vegetativo, na Flórida, ocorreu principalmente na primavera e verão, originando uma a três vegetaçōes.

SIMÃO (1960) verificou que em quase todas as variedades por ele estudadas, o número de surtos variava de dois a cinco. PRASAT \& PATAK (1970), na Índia, verificaram 5 surtos de gemas vegetativas nas variedades Dashehari e Chausa, sendo que o principal ocorreu de março a maio. SRIVASTAVA et al. (1988), estudando as características de 25 porta-enxertos, 13 mono e 12 polembriônicos na altura, circunferencia do cavalo e do enxerto e diâmetro da planta, concluíram que nenhum dos cavalos estudados afetou significativamente as características da variedade estudada Dasheari.

SAMADDAR \& CHAKRABATI (1988) afirmaram que o porta-enxerto é importante no desenvolvimento da planta e adaptação ao solo. Estes autores verificaram que 0 porte das duas copas estudadas, Langra e Himsagar, enxertadas sobre $M$. sylvatica e Langra apresentaram os seguintes resultados. Himsagar desenvolveu-se melhor sobre $M$. sylvatica, enquanto Langra teve melhor desenvolvimento sobre si propria, isto $E$, quando enxertada sobre Langra.

KOHLI \& REDDY, (1988), estudaram oito cavalos de mangueira, durante 8 anos $e$ verificaram não existir nenhuma correlação significativa entre cavalo e copa em relação ao tamanho da planta e produção. Não encontraram também diferença no comprimento dos ramos.

SIMÃO (1971) utilizou sementes verdes de manga, para determinar a possibilidade da mesma em germinar. Segundo o autor, na época da maturação, $20 \%$ dos frutos caem, e não são aproveitados. O seu uso como porta-enxerto seria uma boa opção. Do estudo feito verificou-se que 80\% das sementes, retiradas dos frutos ainda verdes, germinaram.

\section{MATERIAL E METODOS}

O ensaio foi conduzido no pomar do Departamento de Horticultura da ESALQ/USP.

O solo, segundo RANZANI et al. (1966) pertence ao grande grupo Latossolo, série "Luiz de Queiroz" com topografia levemente ondulada. Longitude $47^{\circ} 38^{\prime} 00 \mathrm{~W}$, latitude $22^{\circ} 42^{\prime} 09 \mathrm{~S}$, altitude de $540 \mathrm{~m}$.

Pela classificação climática de Köeppen, o clima da região é Cwa, isto $E$, sub-tropical úmido com estiagem no inverno, com a temperatura média, do més mais quente, superior a $22^{\circ} \mathrm{C}$, e a do mês mais frio, inferior a $1^{\circ} \mathrm{C}$, também denominado de tropical de altitude por CAMARGO et al. (1977).

Foram utilizadas seis variedades: Extrema, Pahiri, Imperial, Oliveira Neto, Carlota e Bourbon, enxertadas sobre: Espada, Extrema, Oliveira Neto, Carlota, Bourbon, Coco e Pahiri. Todas as variedades descritas por SIMÃO (1955).

O delineamento experimental adotado foi o de blocos casualizados, em parcelas subdivididas com 42 tratamentos e 5 repetições. Como parcelas, foram usadas copas e como subparcelas os portaenxertos. $O$ espaçamento utilizado foi $10 \times 10 \mathrm{~m} \mathrm{e}$ usou-se uma planta por parcela.

O experimento foi avaliado em pomar instalado em 1966.

Durante a condução do experimento, os dados de altura e diâmetro das copas foram tomados para avaliação da melhor combinação copa $x$ porta-enxerto, em 1981.

Estes parâmetros foram medidos de acordo com a metodologia de Avilán e Mazzi, citados por AVILAN et al. (1981).

A comparação das médias de copas e ou porta-enxertos foi feita atraves do teste de Tukey, em nível de 5\% de probabilidade.

\section{RESULTADOS E DISCUSSÃO}

Os tratamentos Pahiri como copa e a Bourbon como porta-enxerto, devido ao número de falhas, foram eliminados para efeito de análise estatística.

Os dados de altura da copa referentes ao ano de 1981, apresentaram teste F significativo em nível de $1 \%$ de probabilidade para copas e significativo em nível de $5 \%$ de probabilidade, para porta-enxertos; não houve significância para a interação copa x porta-enxerto, conforme TABELA 1.

A comparação das médias de altura de copa, pelo teste Tukey (TABELA 2) mostrou que as copas das variedades Extrema, Oliveira Neto e Bourbon, não diferiram entre si e diferiram, estatisticamente, em nível de $5 \%$ de probabilidade, das variedades Imperial e Carlota.

$\mathrm{Na}$ comparação das médias do portaenxerto (TABELA 3), s6 houve diferença entre Pahiri e Oliveira Neto, em nível de $5 \%$ de probabilidade.

O diâmetro da copa, apresentou teste $F$ significativo em nível de $1 \%$ de probabilidade para 
as copas, entretanto, não houve significância para porta-enxertos e interação copa $x$ porta-enxertos (TABELA 4).

TABELA 1 - Análise de variância para altura de copa de magueira com 15 anos de idade do ano de 1981.

\begin{tabular}{lrrrr}
\hline $\begin{array}{l}\text { Causas de } \\
\text { variação }\end{array}$ & G.L. & SQ & QM & F \\
\hline Blocos & 4 & 0,5721 & 0,1430 & - \\
Copas (C) & 4 & 85,4444 & 21,3611 & $40,37^{* *}$ \\
Resíduo (a) & 16 & 8,4656 & 0,5291 & \\
\hline Porta-enxerto (P) 5 & 0,9489 & 0,9489 & $2,37^{*}$ \\
Interação C x P & 20 & 0,3994 & 0,3994 & 0,996 ns \\
Resíduo (b) & 86 & 34,4836 & 0,4010 & \\
\hline$m=6,1279$ & & & & \\
C.V. $=11,87 \%$ & & & \\
C.V. $=10,33 \%$ & & & \\
\hline
\end{tabular}

TABELA 2 - Teste de Tukey para as médias de altura de copa de mangueira.

\begin{tabular}{lcc}
\hline Variedades & Média (m) & Tukey (5\%) \\
\hline Extrema & 6,984 & $\mathrm{a}$ \\
Oliveira Neto & 6,785 & $\mathrm{a}$ \\
Bourbon & 6,460 & $\mathrm{a}$ \\
Imperial & 5,224 & $\mathrm{~b}$ \\
Carlota & 5,066 & $\mathrm{~b}$ \\
\hline
\end{tabular}

TABELA 3 - Teste de Tukey para as médias de alturas de copas (m) dos portaenxertos de mangueira.

\begin{tabular}{lrc}
\hline Variedades & Média (m) & Tukey (5\%) \\
Pahiri & 6,350 & a \\
Extrema & 6,316 & ab \\
Coco & 6,206 & ab \\
Espada & 6,126 & ab \\
Carlota & 6,018 & ab \\
Oliveira Neto & 5,784 & b \\
\hline
\end{tabular}

A comparação das médias pelo teste de Tukey (TABELA 5), mostrou que as copas das variedades Oliveira Neto, Extrema e Bourbon, não diferiram entre si, mas a primeira diferiu estatisticamente, em nível de $5 \%$ de probabilidade de Imperial e Carlota, enquanto Extrema diferiu de Carlota.

TABELA 4 - Diâmetro da copa de mangueira do ano de 1981.

\begin{tabular}{lcrrr}
\hline Causas de variação & G.L. & \multicolumn{1}{c}{ SQ } & \multicolumn{1}{c}{ QM } & F \\
\hline Blocos & 4 & 1,5965 & 0,3991 & \\
Copas (C) & 4 & 40,6119 & 10,1530 & $7,21^{* *}$ \\
Resíduo (a) & 16 & 22,5401 & 1,4087 & \\
\hline Porta-enxerto (P) & 5 & 6,8917 & 1,3783 & $1,80 \mathrm{~ns}$ \\
Interação C x P & 20 & 14,9683 & 0,7484 & $0,976 \mathrm{~ns}$ \\
Resíduo (b) & 86 & 65,9218 & 0,7665 & \\
\hline
\end{tabular}

$\mathrm{m}=9,1985$

C.V. $=12,90 \%$

C. $\mathrm{V}_{\mathrm{b}}=9,52 \%$

TABELA 5 - Teste de Tukey para as médias de diâmetro da copa de mangueira (m) das copas.

\begin{tabular}{lcc}
\hline Variedades & Média (m) & Tukey (5\%) \\
\hline Oliveira Neto & 9,9923 & a \\
Extrema & 9,6423 & ab \\
Bourbon & 9,0466 & abc \\
Imperial & $\mathbf{8 , 8 4 8 0}$ & bc \\
Carlota & $\mathbf{8 , 4 6 3 6}$ & $\mathrm{c}$ \\
\hline
\end{tabular}

Como se observa, os dados de diâmetro e altura de copa nas variedades Oliveira Neto, Extrema e Bourbon foram maiores que para as outras variedades (TABELAS 2 e 5), indicando isto, maior desenvolvimento vegetativo até 1981.

A variedade Carlota é de todas a de menor porte e a variedade Imperial apresenta copa mais achatada.

\section{CONCLUSÕES}

De acordo com as observações e anotações durante o trabalho, pode-se tirar as seguintes conclusões:

1) Os dados de diâmetro e altura da copa das variedades Oliveira Neto, Extrema e Bourbon foram maiores que para as outras variedades como 
Carlota e Imperial, indicando maior desenvolvimento vegetativo.

2) O desenvolvimento da copa em altura e em diâmetro está ligado ao porte da variedade.

3) A variedade Pahiri quando utilizada como copa apresentou baixo índice de afinidade, quebrando-se com facilidade.

4) A variedade Bourbon como porta-enxerto foi a mais vulnerável à doença "Seca da Mangueira".

5) Pelos resultados obtidos pode-se utilizar as sementes das variedades copa em estudo, como porta-enxerto para si, assim como para uma outra variedade.

\section{REFERÊNCIAS BIBLIOGRÁFICAS}

AVILÁN, L.; FIGUEROA, M.; SABOREM, B. Consideraçōes acerca de los sistemas de plantacion en mango. Fruits, Paris, v.36, n.3, p.171-179, 1981.

CAMARGO, A.P.; PEDRO, M.J.; ALFONSI, R.R.; ORTOLANI, A.A.; PINTO, H.S. Zoneamento agrícola do estado de São Paulo, aptidão climática. São Paulo: Secretaria do Estado de São Paulo, n.2, 1977. 131p.

KOHLI, R.R.; REDDY, Y.T.N. Influence of rootstocks on growth, yield and leaf nutrient composition of Alphonso Mango. Acta Horticulturae, Wageningen, n.231, p.225-231, 1988.

PRASAT, A.; PATAK, R.A. Biennial bearing of mango tropical agricultural. Paradeniya, Ceilão, v.126, p.35-56, 1970.

RANZANI, G.; FREIRE, O.; KINJO, T. Cartas de solos do Municipio de Piracicaba, Piracicaba: ESALQ/USP, 1966. 25p.
RUEHLE, A.D.; LEDIN, R.B. Mango growing in Forida. Gainesville: Florida Agricultural Experiment Station, 1955. 90p. (Bulletin, 574).

SAMADDAR, H.N.; CHAKRABATI, W. Effect of different rootstocks on hinsagar and Langria. Acta Horticulturae, Wageninger, n.231, p.220-224. 1988

SMMÃo, S. Contribuição para caracterização de algumas variedades de mangueira (Mangifera indica L.) Piracicaba, 1955, 96 p. Tese (Livre-Docência) Escola Superior de Agricultura "Luiz de Queiroz", Universidade de São Paulo.

SIMÃO, S. Estudos da planta e do fruto da mangueira, (Mangifera indica L.). Piracicaba, 1960, 167p. (Catedra) - Escola Superior de Agricultura "Luiz de Queiroz", Universidade de São Paulo.

SIMÃo, S. Manual de fruticultura. São Paulo: Ceres, 1971. 530p.

SIMĀO, S. Situação da cultura da mangueira no Brasil. In: SIMPOSIO BRASILEIRO SOBRE A CULTURA DA MANGUEIRA, 1980, Jaboticabal. Anais... Jaboticabal: UNESP, 1980. p.3-11.

SINGH, L.B. The mango, botany, cultivation and utilization. London: Leonard Hill, 1967. 438p.

SRIVASTAVA, K.C.; RAPPUT, M.S.; SURGLE, N.P.; LEAL, B. Rootstock Studies in mango cv. Dasheari. Acta Horticulturae, Wageningen, v.231, p.216-219, 1988.

Recebido para publicação em 13.12 .93

Aceito para publicação em 17.08.94 